\title{
Functional and histopathological changes induced by intraparenchymal injection of kainic acid in the rat cervical spinal cord
}

\author{
Fabián Nishida a,c,* Carolina N. Zanuzzi ${ }^{\mathrm{a}, \mathrm{b}, \mathrm{c}}$, Agustín Martínez $^{\mathrm{d}}$, Claudio G. Barbeito ${ }^{\mathrm{a}, \mathrm{b}, \mathrm{c}}$, \\ Enrique L. Portiansky ${ }^{a, c}$
}

${ }^{a}$ Image Analysis Laboratory, School of Veterinary Sciences, National University of La Plata (UNLP), Buenos Aires, Argentina

${ }^{\mathrm{b}}$ Department of Histology and Embryology, School of Veterinary Sciences, National University of La Plata, Buenos Aires, Argentina

${ }^{\mathrm{c}}$ National Research Council of Science and Technology (CONICET), Argentina

d National Institute of Agricultural Technology (INTA), Bariloche, Argentina

\section{A R T I C L E I N F O}

Article history:

Received 20 November 2014

Accepted 12 May 2015

Available online 23 May 2015

\section{Keywords:}

Kainic acid

Cervical segments

Spinal cord

Morphometric analysis

Rat

\begin{abstract}
A B S T R A C T
Kainic acid (KA) is an analog of the neurotransmitter glutamate and is widely used as an excitotoxic agent to lesion spinal cord networks, thus, providing an interesting model to learn basic mechanisms of spinal cord injury. The present work was aimed to evaluate motor and sensory performance of rats and analyze morphometric parameters of spinal cord neurons after KA injection. Animals were injected either with $0.75,1$ or $1.25 \mathrm{mM}$ of KA at the C5 segment of the cervical spinal cord. Motor and sensory performance of the rats were evaluate at day 0 (before injection) and at days 1, 2, 3 and 7 post-injection (pi) and compared with those of saline-treated and non-operated animals. Animals were sacrificed at each time point for morphometric and histopathological analysis and compared among groups. All KAtreated animals showed a significant impairment at the motor and sensory tests for the ipsilateral forelimb in a concentration-dependent manner in comparison to saline-treated and non-operated animals. Neuronal cell count showed a significant loss of neurons at C4, C5 and C6 cervical segments when compared with those of saline-treated and non-operated animals. The contralateral side of the cervical segments in KA-treated rats remained unchanged. Some improvement at the motor and sensory tests was observed in animals injected with 0.75 and $1 \mathrm{mM} \mathrm{KA}$. Moreover, a mild increase in the neuronal count of the damaged segments was also recorded. The improvement recorded in the motor and sensory tests by day 7 pi may be a consequence of a neuron repairing mechanism triggered soon after the KA excitotoxic effect.
\end{abstract}

(c) 2015 Elsevier Inc. All rights reserved.

\section{Introduction}

Kanic acid (KA) is a cyclic analog of the major stimulatory brain neurotransmitter glutamate. It acts on neuronal receptors inducing an excitotoxic effect, causing neuronal death in different regions of the CNS (Bayrakdar et al., 2013; Ben-Ari and Kainate, 2000; Kuzhandaivel et al., 2010; Pereno et al., 2011). Taccola et al. (2008) showed that $24 \mathrm{~h}$ after a time-constrained $(1 \mathrm{~h})$ kainate application,

\footnotetext{
* Corresponding author at: Laboratorio de Análisis de Imágenes, Facultad de Ciencias Veterinarias, Universidad Nacional de La Plata, Calles 60 y 118, $1900 \mathrm{La}$ Plata, Argentina. Tel.: +54 221423 6663x426; fax: +54 2214237980 .

E-mail addresses: fnishida@fcv.unlp.edu.ar (F. Nishida),

carozanuzzi@fcv.unlp.edu.ar (C.N. Zanuzzi), martinez.agustin@inta.gob.ar

(A. Martínez), barbeito@fcv.unlp.edu.ar (C.G. Barbeito), elporti@fcv.unlp.edu.ar (E.L. Portiansky).
}

KA causes extensive neuronal network damage and early irreversible loss of neuronal activity. It has been shown that high extracellular concentrations of glutamate evoke spinal damage in vivo (Liu et al., 1999; Matsui et al., 2005). KA induces an intracellular influx of $\mathrm{Ca}^{2+}$ that leads to the production of free radicals, the hyperactivation of the intracellular enzymes poly (ADP) ribose polymerase- 1 and ATPase, thus triggering energy failure, DNA damage and neuronal death (Mazzone and Nistri, 2011; Mitra et al., 2013).

Different experimental methods have been used to study spinal cord injury (SCI) and neurodegenerative diseases. Some of the most commonly experimental models used are the weight drop (contusion) (Chvatal et al., 2008; von Euler et al., 1996), the transection of the dorsal section of the spinal cord (Kunkel-Bagden et al., 1993; Schrimsher and Reier, 1993) and the injection of a specific compound into the spinal cord (neurotoxin) (Klein et al., 2009). Thus, a reliable test protocol, suitable for the injury model is 
essential for proper evaluation of motor and sensory dysfunctions, as well as functional recovery after $\mathrm{SCI}$.

At present, KA is used as a useful model to replicate glutamate excitotoxicity in in vivo models, in neuron cultures as well as in isolated organotypic slices of spinal cord (Calderó et al., 2010; Kuzhandaivel et al., 2010; Magnuson et al., 1999; Mazzone et al., 2010; Taccola et al., 2008). Mazzone et al. (2010) were able to evoke a reproducible pattern of spinal network lesions, and to assess the functional outcomes in terms of motor neuronal network activity in vitro.

Although KA is known as a neurotoxic drug, to our knowledge there are no reports of its effects after intraparenchymal injection in the rat cervical spinal cord. There are few reports using KA with the intrathecal via (Mitra et al., 2013), and others using intraparenchymal injection of KA analogs, such as AMPA, quisqualic acid and NBQX (Corona and Tapia, 2004; Hirata et al., 1997). The aim of the present research was to perform a systematic study of motor and sensory functional changes and histopathological lesions that different concentrations of KA may cause at the C 5 cervical segment of inoculated rats. The data are expected to be relevant for the design of future trials for the prevention and treatment of other neurodegenerative diseases at the cervical spinal cord.

\section{Materials and methods}

\subsection{Animals}

Young (3-4 mo. 200-300 g) ( $n=75)$ male Sprague-Dawley rats, raised in our rat colony, were used. Animals were housed in a temperature-controlled room $\left(22 \pm 2{ }^{\circ} \mathrm{C}\right)$ on a $14: 10 \mathrm{~h}$ light/dark cycle. Food and water were available ad libitum. All experiments with animals were performed according to the recommendations of the Guide for the Care and Use of Laboratory Animals of the National Institutes of Health. The protocol was approved by the Committee on the Ethics of Animal Experiments of INIBIOLP's Animal Welfare Assurance No. A5647-01.

\subsection{Toxin administration}

On experimental day 0 , rats were anesthetized with ketamine hydrochloride ( $40 \mathrm{mg} / \mathrm{kg}$; ip) plus xylazine $(8 \mathrm{mg} / \mathrm{kg}$; im) and placed in prone position. Kainic acid injection was performed as previously described (Nishida et al., 2014). Briefly, to gain access to the C5 segment a trepanation at the C4-C5 fibrous joint $1 \mathrm{~mm}$ lateral from the midline (dorsal spinal process) of the vertebral column was performed. For injecting the solution a $10 \mu \mathrm{l}$ Hamilton ${ }^{\circledR}$ syringe fitted with a $26 \mathrm{G}$ needle was hand-held. At certain distance from the tip, the needle had a mark to indicate the limit of penetration into the spinal cord. The needle was vertically introduced $1.5 \mathrm{~mm}$ down on the right side of the spinal cord in order to reach the Lamina-VI of that side (ipsilateral). Once introduced into the spinal cord, the needle was held in place for $2 \mathrm{~min}$. The discharge of the solution lasted for $5 \mathrm{~min}$. Before removing the needle it was held in place for 2 more min to avoid leaking of the solution. Five microliters either of the KA solution or saline were discharged at that point at a rate of $1 \mu \mathrm{l} / \mathrm{min}$. In all cases, the histological feature of the needle trace was checked to determine the accuracy of the technique. After surgery animals were returned to their cages and checked periodically until they woke up. In no case animals required manual emptying of the bladder.

\subsection{Drug injection}

Kainic acid (Sigma-Aldrich, Inc., St. Louis, MO. USA) was dissolved in $0.9 \%$ saline and kept at $4{ }^{\circ} \mathrm{C}$ until use. Animals were injected either with $0.75 \mathrm{mM}$ KA (KA0.75); $1 \mathrm{mM} \mathrm{KA} \mathrm{(KA1),}$ $1.25 \mathrm{mM}$ KA (KA1.25) or saline (saline-injected group). The selection of the kainate concentrations was based on the results reported by Taccola et al. (2008), who found the appropriate concentration to induce an irreversible loss of motor activity. Five rats of each KA group were sacrificed either at 1, 2, 3 or 7 postinjection (pi) days. Three rats of the saline-injected group were killed at the same time points. Three non-operated animals were used as a control group in all experiments.

\subsection{Clinical assessment}

\subsubsection{Weight measurement}

All control and experimental animals were weighed before surgery (day 0 ) and at every pi time point before sacrifice.

\subsubsection{Behavioral tests}

All rats were submitted to a set of motor and sensory tests adapted from Biesiadecki et al. (1999), Sedý et al. (2008) and Wallace et al. (1980) before and after treatment at each sacrifice time point.

2.4.2.1. Withdrawal reflex. Withdrawal reflexes are a group of stimulus-based reflex response reactions. To evaluate these reflexes the speed and the force of limb withdrawal after extension, pain, or pressure were assessed. To this end we pricked the foot pad with a needle (pain). The reflex response was considered as $0=$ no withdrawal; $1=$ normal withdrawal; -1 = delayed withdrawal (Gale et al., 1985; Von Euler et al., 1996).

2.4.2.2. Heat sensitivity test. The hot-plate test was carried out according to the method previously described (Milano et al., 2008). In these experiments, the hot-plate apparatus was set at $55 \pm 1{ }^{\circ} \mathrm{C}$. Animals were placed on a $15 \mathrm{~cm}$ diameter heated surface surrounded by four acrylic walls, and the time (measured in s) between placement (time zero) and licking of their forepaws or jumping (whichever occurred first), was recorded and considered as the response latency. A 20 s cut-off was used to prevent tissue damage. Three measures at 2-min-intervals were taken before (baseline) and after drug treatment and their means were considered as basal or experimental latencies, respectively.

2.4.2.3. Suspension from a horizontal wire mesh pole. The time during which rats could sustain their own weight was determined by placing the animals on a horizontal wire mesh pole. An $8 \mathrm{~cm}$ diameter pole was covered by a nylon mesh (pore size: $0.5 \mathrm{~cm}$ ). The pole was immediately rotated so as the animals were left suspended from the wire mesh $50 \mathrm{~cm}$ over a water tank (Nishida et al., 2011). The latency taken by the animals to fall was recorded as the average of three consecutive sessions.

2.4.2.4. Ladder rung walking test. This test was carried out to examine forelimb coordination during skilled walking in rats. The horizontal ladder rung walking test device has side walls made of clear acrylic and metal rungs ( $3 \mathrm{~mm}$ diameter) which could be inserted to create a floor with a minimum distance of $1 \mathrm{~cm}$ between rungs. The side walls were $1 \mathrm{~m}$ long and $19 \mathrm{~cm}$ high measured from the height of the rungs. The ladder was placed $30 \mathrm{~cm}$ above the ground. The width of the alley was $1 \mathrm{~cm}$ wider than the rat to prevent the animal from turning around. Rats were trained to walk across the ladder rung walking device three times per session for a week before experimental day 0 .

Limb coordination and skilled walking patterns for the forepaw were analyzed according to a scoring system published by Metz and Whishaw (2002) ranging from 0 (abnormal) to 6 (perfect). All scores between 0 and 2 were considered to be an error (total miss, 

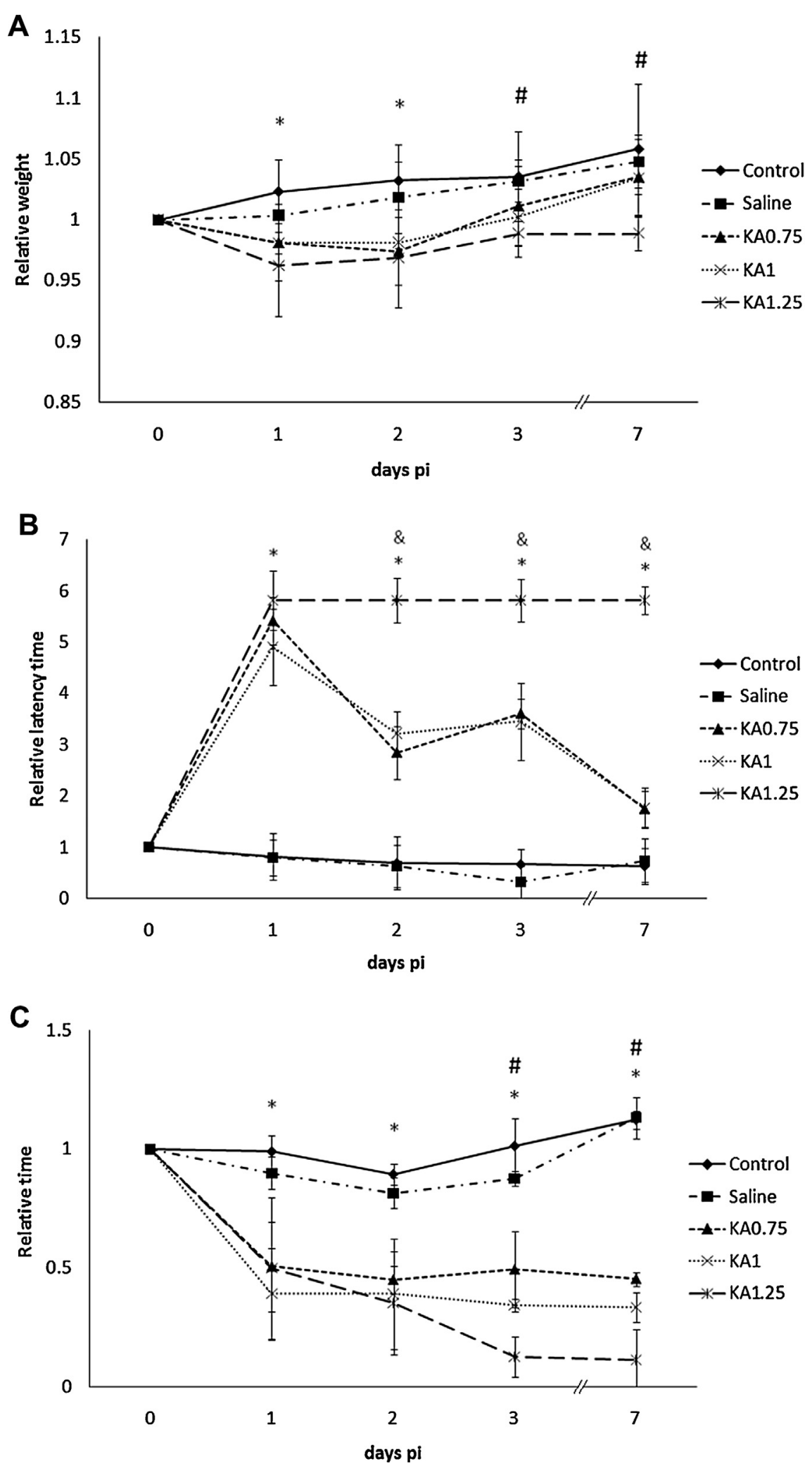

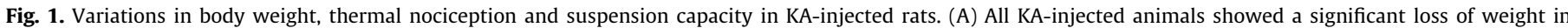

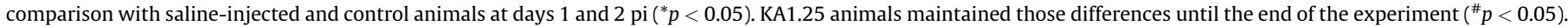

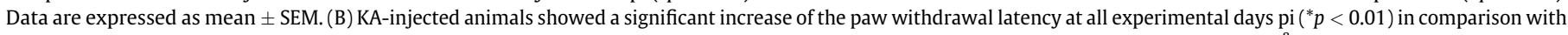

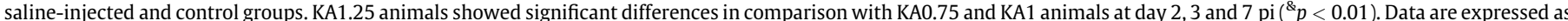

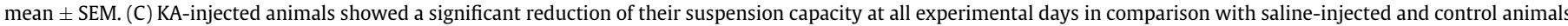

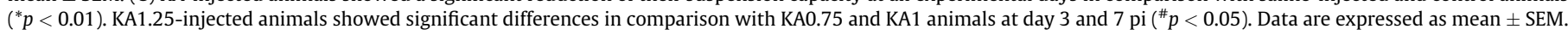


deep slip, and slight slip from the rung) (Klein et al., 2009). Two different parameters were used to evaluate the movements of the contralateral and the ipsilateral limbs: the number of errors as percent of the total number of steps made in each trial and the total score (per step group and experimental day). The video recording was taken from a lateral view with a digital video camera, and the shutter speed was set at $30 \mathrm{f} / \mathrm{s}$. The recordings were analyzed frame-by-frame to classify all the steps per group.

\subsubsection{Specimen collection and processing}

Sacrifice was performed according to the Guidelines on the Use of Animals in Neuroscience Research (the Society of Neuroscience) and the Research Laboratory Design Policy and Guidelines of NIH. Immediately before sacrifice rats were placed under general anesthesia by injection of ketamine hydrochloride $(40 \mathrm{mg} / \mathrm{kg}$, i.p.) plus xylazine ( $8 \mathrm{mg} / \mathrm{kg}$; i.m.) and then intracardially perfused with a buffered saline-paraformaldehyde $4 \%$ solution for approximately 30-45 min. The vertebral column was then removed and postfixed in $10 \%$ buffered formaldehyde for $24 \mathrm{~h}$. The spinal cord was then dissected, immersed in cryopreservation buffer (sucrose 30\%; polyvinylpyrrolidone $1 \%$; ethylene glycol $30 \%$ phosphate buffer $1 \mathrm{M} 1 \%$; DW to $100 \mathrm{ml}$ ) and stored at $-20^{\circ} \mathrm{C}$ until use.

Coronal sections of cervical segments were performed under a magnifying glass. Every segment was placed at the center of one well of a 48-well plate. The well was then filled with $0.5 \mathrm{ml}$ jellifying solution (sucrose $10 \%$ in phosphate buffer $1 \mathrm{M}$; low melting point agarose [Sigma Chemical Co., St. Louis, MO] 4\%). After $24 \mathrm{~h}$ storage at $4{ }^{\circ} \mathrm{C}$ the jelly blocks were serially cut into $20 \mu \mathrm{m}$ thick coronal sections using a vibratome (Leica VT 1000S, Germany). Sections were then mounted on jellified slides (unflavored gelatin $6 \mathrm{~g} ; \mathrm{KCr}\left(\mathrm{SO}_{4}\right)_{2} \cdot 12 \mathrm{H}_{2} \mathrm{O} 0.5 \mathrm{~g}$, DW to $300 \mathrm{ml}$ ).

Some sections were stained with the cresyl violet technique and used for cell counting and morphometric analysis. From each block, three to five sections, $120 \mu \mathrm{m}$ apart, were analyzed. Myelin was stained by Luxol Fast Blue staining for a qualitative analysis.

\subsubsection{Immunohistochemistry}

Spinal cord sections were mounted on jellified slides (unflavored gelatin $6 \mathrm{~g} ; \mathrm{KCr}\left(\mathrm{SO}_{4}\right)_{2} \cdot 12 \mathrm{H}_{2} \mathrm{O} 0.5 \mathrm{~g}$, DW to $300 \mathrm{ml}$ ) and incubated with $0.03 \% \mathrm{H}_{2} \mathrm{O}_{2}$ in PBS for $30 \mathrm{~min}$ at room temperature. Sections were then rinsed twice in PBS and incubated with Proteinase $\mathrm{K}$ (Thermo Scientific ${ }^{\mathrm{TM}}$, CA, USA) for $20 \mathrm{~min}$ at room temperature for antigen retrieval. Afterwards, section were washed twice in PBS and incubated with 1\% BSA in PBS for $30 \mathrm{~min}$, followed by overnight incubation with anti-NeuN antibody (monoclonal mouse Clone A60, Millipore, CA, USA). The EnVision detection system + HRP system labeled anti-mouse polymer (DakoCytomation) was applied for $30 \mathrm{~min}$. Sections were then rinsed threefold in PBS. Liquid 3,3-diaminobenzidine tetrahydrochloride (DAB) (Vector Laboratories Inc., CA, USA) was used as chromogen and Hill's hematoxylin for counterstaining. Control negative sections were prepared by omitting primary antibody.

\subsubsection{Image analysis}

Images of cresyl violet, Luxol Fast Blue and immunohistochemically stained spinal cord sections were captured using a digital RGB video camera (Olympus DP71, Japan) attached to a microscope (Olympus BX50, Japan). In order to create a complete map of the entire segment taken with a $40 \times$ objective, images were captured using a digital image analyzer (cellSens Dimension, V1.7, Olympus Corporation, Japan) and stitched using an automatic Multiple Image Alignment process. No further processing was necessary after obtaining the original images.

For counting and morphometric determinations the entire segment was analyzed. In order to determine the morphometric characteristics of neuronal bodies, segmentation based on color was performed (Portiansky, 2013). Neurons were then characterized using the following parameters: cellular area (reports the area of each object), feret diameter (reports the caliper length of the object), roundness (reports the roundness of each object, as determined by the following formula: (perimeter $\left.{ }^{2}\right) /\left(4^{*} \pi^{*}\right.$ area). Circular objects will have a roundness $=1$; other shapes will have a roundness $>1$ ) and cell number. Morphometric data were taken only from those neuronal somata that showed a delineated shape and a distinguishable nucleus. Similarly, only those cells that were recognized by the image analyzer, based on the staining or color pattern and on their size and shape, were included in the analysis. In addition, the observations were done by two independent morphologists, in order to obtain a more objective counting and morphometric characterization. Differentiation between neurons and glial cells was based on their nuclear diameter. Glial nuclear diameter is below $5 \mu \mathrm{m}$ whereas those of neurons are longer (Portiansky et al., 2011).

Three areas of analysis were considered in each section: dorsal gray matter (Paxinos and Watson, (1986) Laminae I-V), central gray matter (Paxinos and Watson, (1986) Laminae VI and X), and ventral gray matter (Paxinos and Watson, (1986) Laminae VII-IX).

To estimate the number of cells present in an entire cervical segment the following formula was used (Sánchez et al., 2003):

$N=\frac{d}{n \cdot s} \sum_{i=1}^{n} x$

being, $N=$ total estimated number of cellular bodies; $d=$ length $(\mu \mathrm{m})$ of the rostrocaudal axis of the segment being assessed; $n=$ number of non-contiguous slices counted per cervical segment $(n=3-5)$. Separation between slices was $120 \mu \mathrm{m} ; s=$ thickness of the section $(20 \mu \mathrm{m}) ; x=$ number of perikarya counted per noncontiguous slice assessed. Therefore, $N$ represents the estimated total number of neurons present in every segment.

\subsubsection{Statistical analysis}

Data expressed as mean \pm S.E. were analyzed by Student $t$-test and one-way analysis of variance (ANOVA). Fisher's LSD for multiple comparisons was used as a post hoc test. For non-parametric values, the Mann-Whitney test and Kruskall-Wallis test were used. Significance was assumed at values of $p<0.05$.

\section{Results}

\subsection{Clinical signs and weight measurement}

As C5 segment contributes with the formation of the phrenic nerve together with $\mathrm{C} 3$ and $\mathrm{C} 4$ segments, particular attention was paid to respiratory behavior of injected animals. None of the KA-injected or saline-injected rats showed abnormal respiratory frequency, made respiratory noises or had an orthopneic stand.

All KA-injected animals showed a significant $(p<0.05)$ loss of weight in comparison to saline-injected and control animals. This

Table 1

Withdrawal reflex test responses for the ipsilateral (IF) and contralateral forelimbs (CF).

\begin{tabular}{|c|c|c|c|c|c|c|c|c|c|c|}
\hline & \multicolumn{2}{|c|}{ Day 0} & \multicolumn{2}{|c|}{ Day 1} & \multicolumn{2}{|c|}{ Day 2} & \multicolumn{2}{|c|}{ Day 3} & \multicolumn{2}{|c|}{ Day 7} \\
\hline & IF & $\mathrm{CF}$ & IF & $\mathrm{CF}$ & IF & $\mathrm{CF}$ & IF & $\mathrm{CF}$ & IF & $\mathrm{CF}$ \\
\hline KA075 & 1 & 1 & 0 & 1 & -1 & 1 & -1 & 1 & -1 & 1 \\
\hline KA1 & 1 & 1 & 0 & 1 & 0 & 1 & -1 & 1 & -1 & 1 \\
\hline KA1.25 & 1 & 1 & 0 & 1 & 0 & 1 & 0 & 1 & 0 & 1 \\
\hline Saline & 1 & 1 & 1 & 1 & 1 & 1 & 1 & 1 & 1 & 1 \\
\hline Control & 1 & 1 & 1 & 1 & 1 & 1 & 1 & 1 & 1 & 1 \\
\hline
\end{tabular}

$0=$ no withdrawal; 1 = normal withdrawal; $-1=$ delayed withdrawal. 


\section{Ipsilateral}
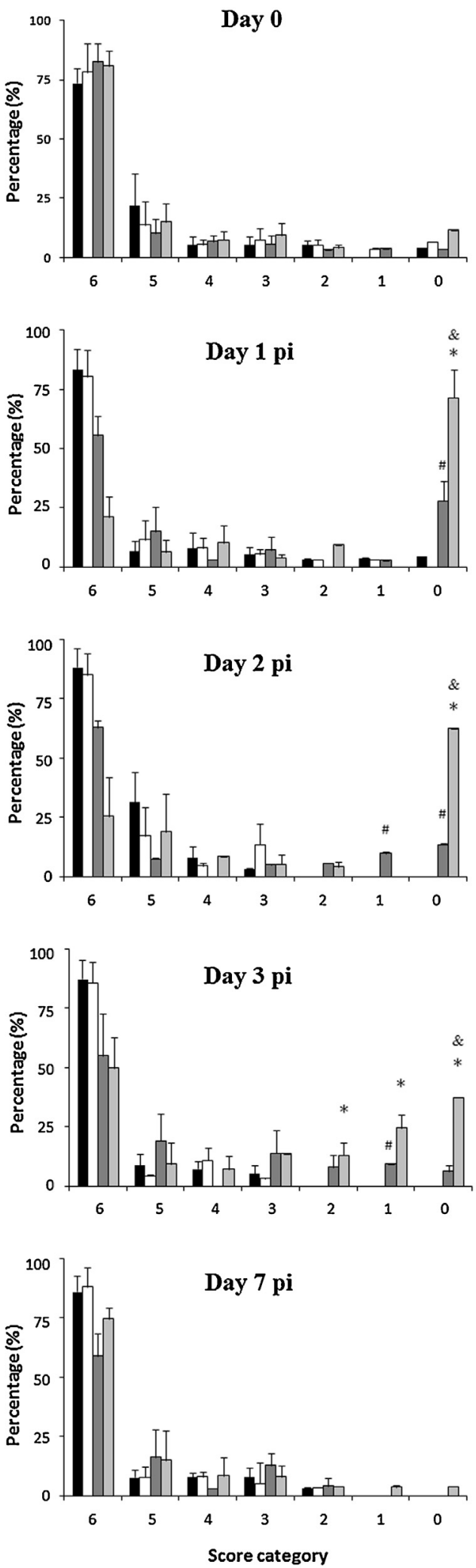

ש Control $\sqcap$ Saline ПKA0.75 ПKA1
Contralateral
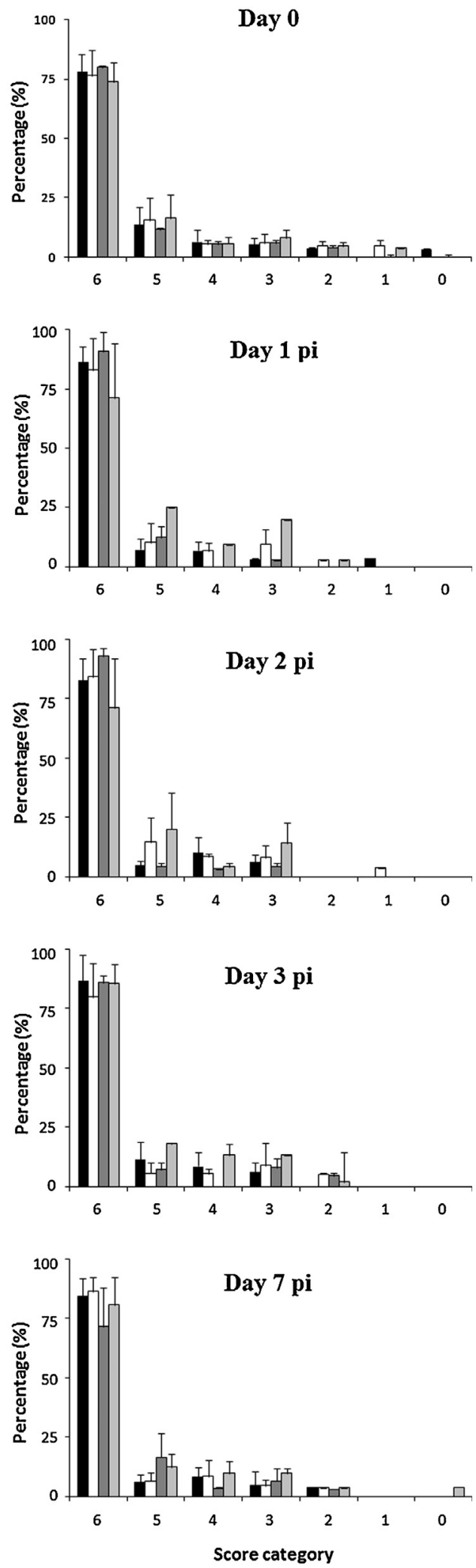

- Control $\square$ Saline $\square$ KA0.75 $\square$ KA1

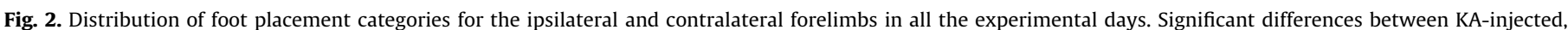

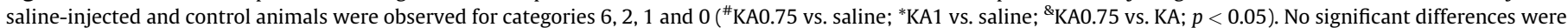
observed for the contralateral forelimb scores between groups. Data are expressed as mean \pm SEM. 


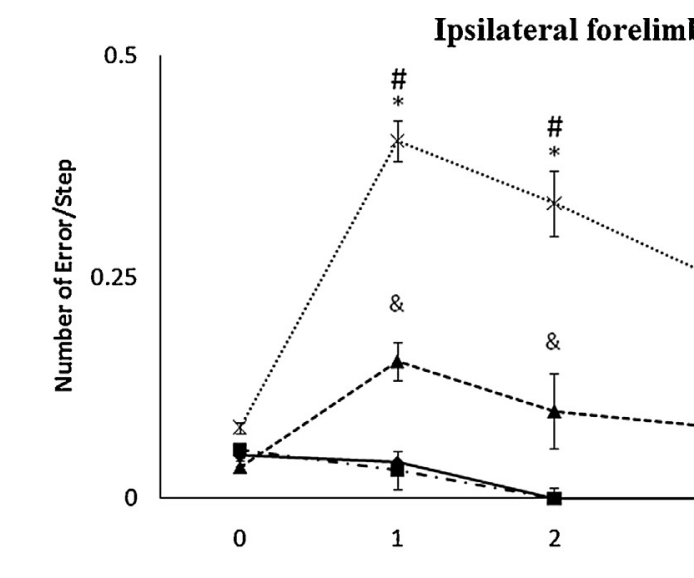

Ipsilateral forelimb

Contralateral forelimb

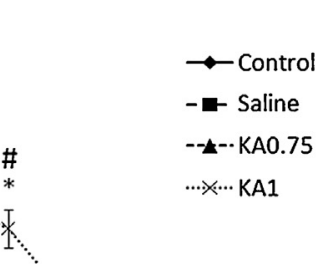

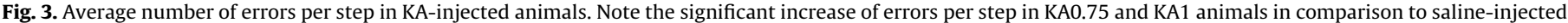

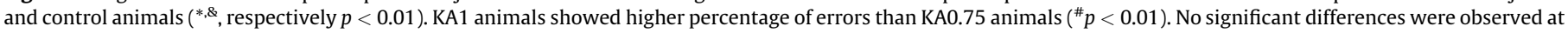
the contralateral forelimb among groups. Data are expressed as mean \pm SEM.

weight loss was recorded at all time points for the KA1.25 group, whereas for KA0.75 and KA1 groups it was found only at days 1 and 2 pi, showing a mild recovery from day 3 to day 7 pi (Fig. 1A). In no case weight differences were higher than $30 \mathrm{~g}$. No significant differences in body weight were observed between saline-injected and control animals.

\subsection{Behavioral tests}

\subsubsection{Withdrawal reflex test}

KA0.75 and KA1 animal groups showed no withdrawal reflex from day 1 up to day 3 pi and a delayed withdrawal reflex by day 7 pi, whereas KA1.25 animal group showed no withdrawal reflex for all the experimental days studied (Table 1). Saline-injected and control groups displayed a normal withdrawal reflex at all pi days.

\subsubsection{Heat sensitivity test}

Highly significant differences were observed between salineinjected and KA-injected groups (Fig. 1B). The paw withdrawal latency increased in all KA-injected animals at day $1 \mathrm{pi}(p<0.01)$. Subsequently, there was a reduction in the latency time in KA0.75 and KA1 animal groups from day 2 up to day $7 \mathrm{pi}$, but values remained above the baseline. No reduction in the paw withdrawal latency was observed for KA1.25 group. No significant differences were observed between saline-injected and control groups.

\subsubsection{Suspension from a horizontal wire mesh pole}

KA injection caused a significant impairment in the suspension capacity of all animals at all days pi $(p<0.01)$. Significant differences were observed between saline-injected and KAinjected groups from day 1 up to day 7 pi (Fig. 1C) Besides,

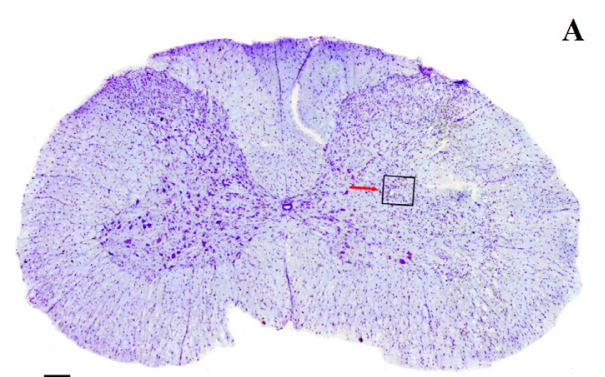

A

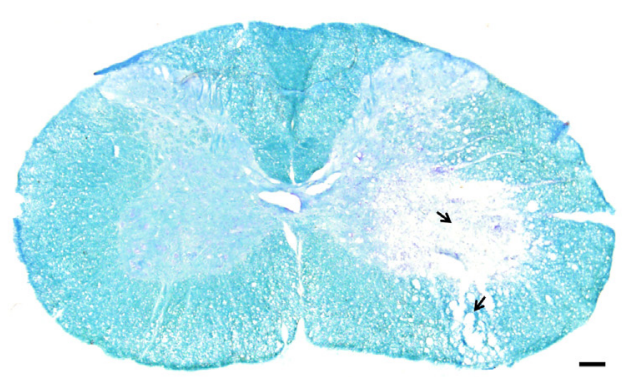

C
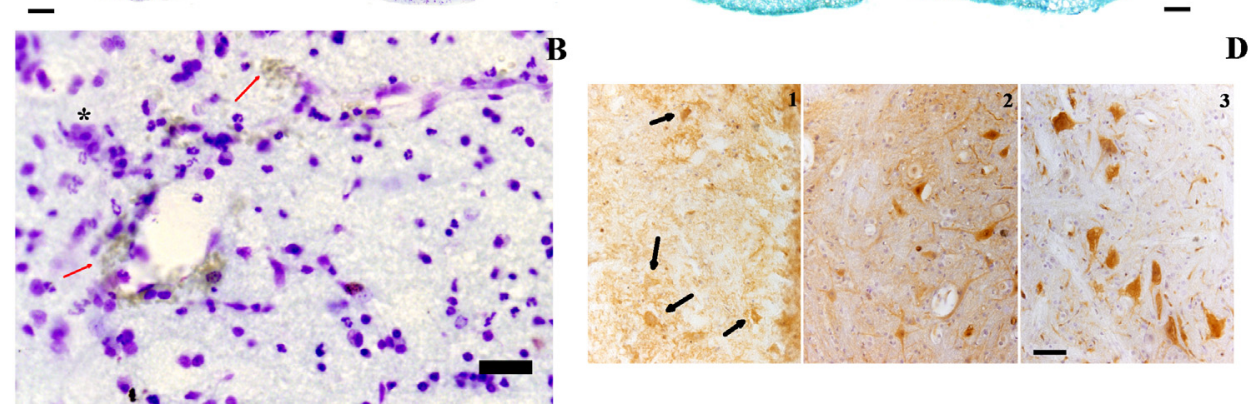

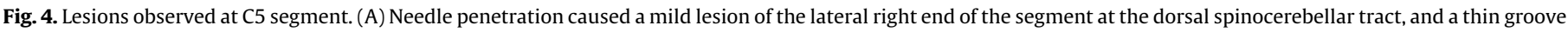

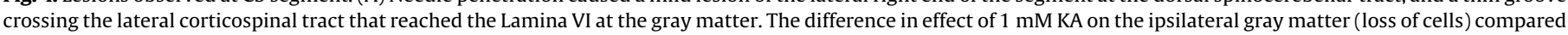

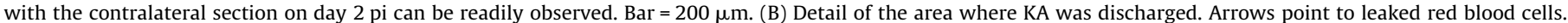

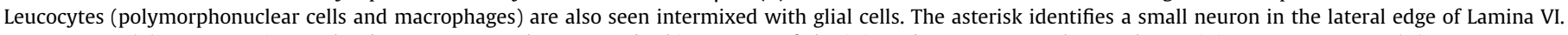

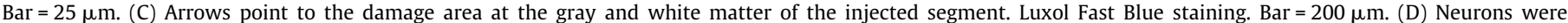

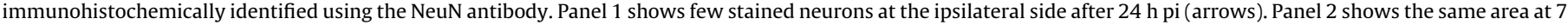
days pi. Panel 3 shows the contralateral side at $24 \mathrm{~h}$ pi. Bar $=50 \mu \mathrm{m}$. 
KA1.25 group showed a significant impairment in the suspension capacity in comparison with KA0.75 and KA1 groups at day 3 and 7 pi. Motor performance in saline-injected animals fell slightly after surgery but no significant differences were recorded at any time point in comparison with the control group.

\subsubsection{Ladder rung walking test}

The unilateral injection of KA into the spinal cord severely impaired the skilled walking performance. Since KA1.25 animals were unable to overpass the ladder they were not included in the analysis. Supplementary Fig. 1 shows the test performed by KA1 and saline-injected animals.

3.2.4.1. Foot fault scores. The most frequent category of foot placement for saline-injected and control groups was perfect (score 6) for ipsi- and contralateral forelimbs throughout all the experiment. No significant differences were observed between KAinjected, saline-injected and control animals for both forelimbs at day 0 (Fig. 2). Significant differences were observed for perfect placement (score 6) and foot-fault (scores 0-2) of the ipsilateral forelimb between saline-injected and KA-injected animals from day 1 up to day 3 pi $(p<0.05)$. In addition, KA1 showed higher percentages of foot-fault in comparison to KA0.75 from day 1 up to day 3 pi. Both KA0.75 and KA1 injected animals showed a mild improvement by day 7 , but it was not statistically significant. No significant differences were observed for any category of contralateral foot placement among groups.

3.2.4.2. Foot placement accuracy analysis (number of errors). The number of errors per step was analyzed as an indicator of foot placement accuracy. Limb placement accuracy of ipsilateral forelimbs showed significant impairments in motor coordination in KA0.75 and KA1 groups $(p<0.01)$ in comparison to salineinjected and control groups (Fig. 3). KA1 animals showed significantly enhanced error rates in comparison with KA0.75 animals $(p<0.05)$ from day 1 up to day 3 pi. No significant differences were observed at day 7 pi among groups. Besides, no significant differences were observed between saline-injected and control animals. The accuracy analysis of contralateral forelimbs showed no significant differences among groups.

\subsection{Histological analysis}

Lesions at C5 consisting on loss of the right upper end of the segment, lateral to the dorsal spinocerebellar tract and a thin groove that crossed the lateral corticospinal tract to reach the Lamina-VI within the spinal gray matter were observed in all injected animals. The described pattern corresponds to the penetration point and the path of the injection needle (Fig. 4A,B). Surrounding the groove and at its end, an infiltrate of polymorphonuclear cells and some red blood cells was detected. Samples from the saline-injected group showed similar histological changes. In the KA-injected groups, debris of neurons or neurons in different stages of degeneration and inflammatory edema were observed in a KA dose-dependent manner. Exudate was found in all of the Laminae except in Lamina-X at which it was absent or less severe than in the rest of the ipsilateral gray matter.

Luxol Fast Blue staining revealed extensive damage of the gray and white matter ventral and ventrolateral tracts at the ipsilateral side of the KA-injected segments (Fig. 4C). The same histological pattern, but with less intensity was observed in contiguous segments (C4 and $\mathrm{C} 6$ ) of the injection site. In the remaining segments of the cervical region as well in all the segments of control animals, no signs of lesions were observed.

Immunohistochemical analysis for identifying NeuN revealed the presence of a scarce number of small neurons in the damaged area on day 1 pi. (Fig. 4D1) and an increase of the background staining. On day 7 pi the number of neurons increased and the background intensity was reduced (Fig. 4D2). The contralateral side of KA-injected rats (Fig. 4D3) and both sides of saline-injected and control rats showed the same staining pattern where neurons were easily identified and the background remained unstained.

\subsection{Image analysis}

The morphometric analysis of the injected segment showed a significant loss of neurons in KA-injected animals at all days pi in comparison to saline-injected or control groups $(p<0.05)$ (Fig. 5A). This loss was observed at the ipsilateral side (Fig. 5B) but not at the contralateral side (Fig. 5C) where no significant differences were observed among groups. This analysis was performed on cresyl violet stained tissues as well as on NeuN antibody immunohistochemically stained neurons. In both cases, counting showed the same pattern.

Loss of neurons was also observed at C4 and C6 segments, both microscopically and after counting (Fig. 6). After drug injection no morphological variations (area, perimeter, feret diameter and roundness) were found in the remaining neurons, in comparison to those of the saline-injected and control groups at any pi time points assessed (Table 2). When dorsal, central and ventral areas of the cervical segments were considered and compared among groups, a significant neuronal loss was detected in the three areas

$\mathbf{A}$
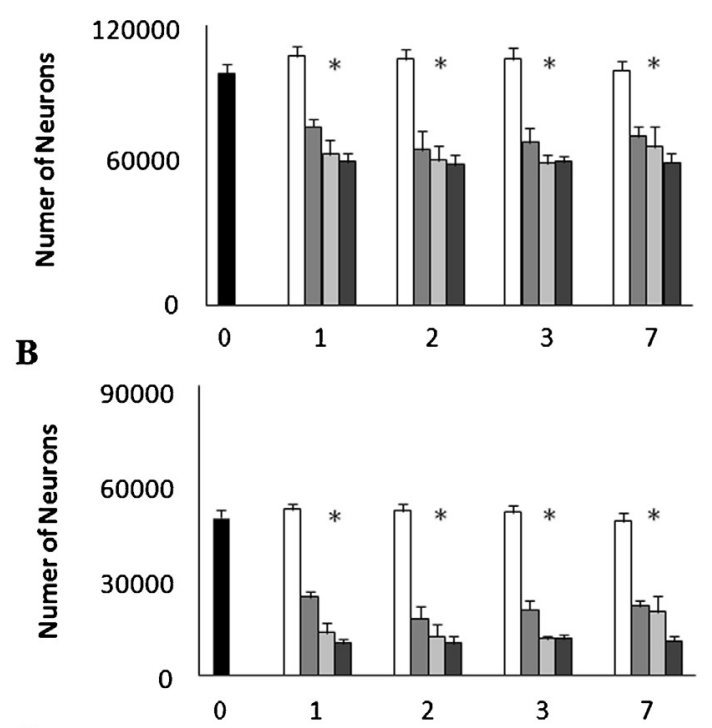

C

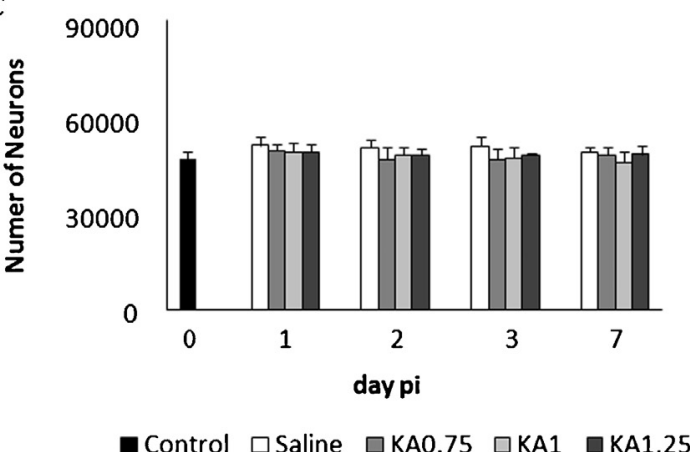

Fig. 5. Neuronal counting at C5. (A) Estimation of the total number of neurons at C5 segment. (B) Estimation of the total number of neurons at the ipsilateral side. (C) Estimation of the total number of neurons at the contralateral side. Data are expressed as mean \pm SEM. ${ }^{*} p<0.05$. 
A

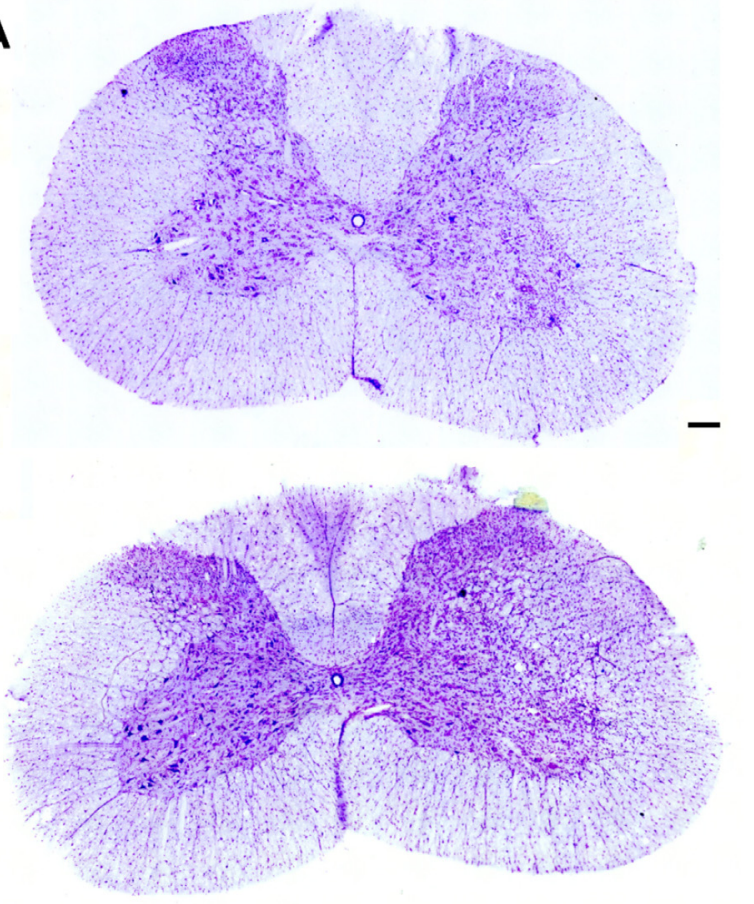

B

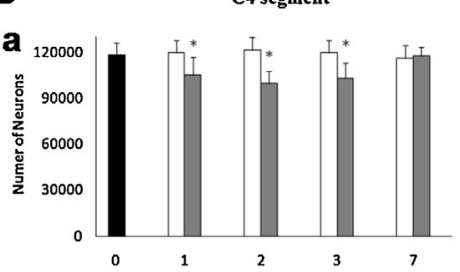

b
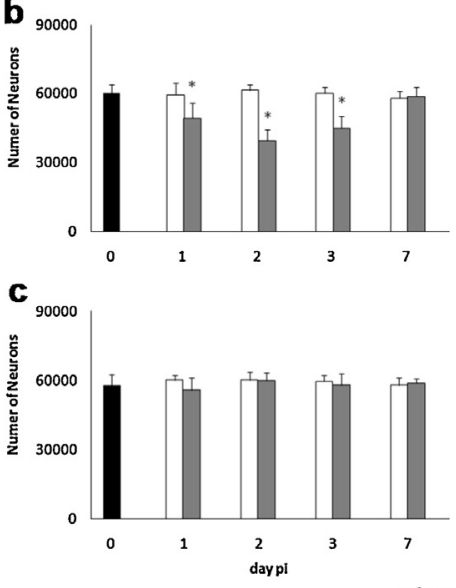
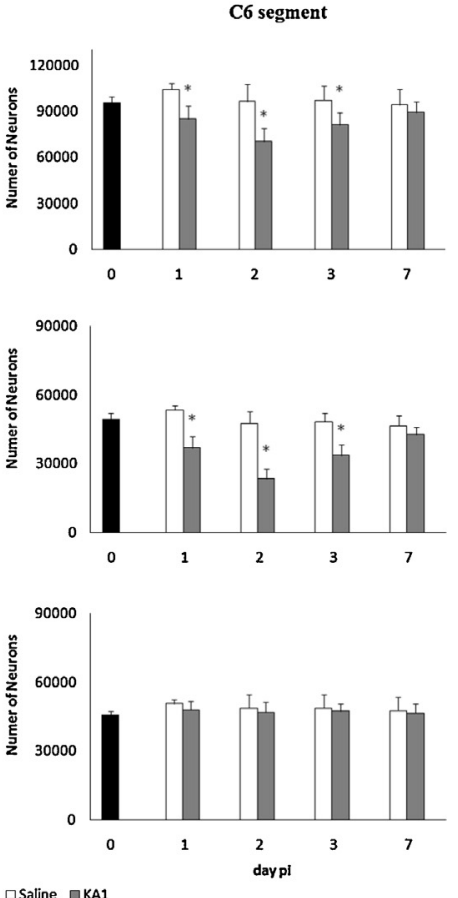

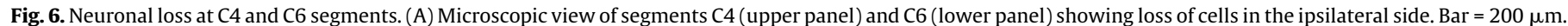

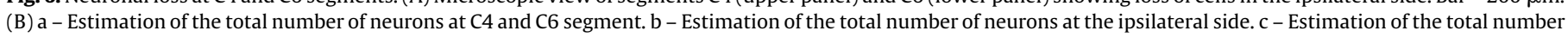
of neurons at the contralateral side. Data are expressed as mean \pm SEM. ${ }^{*} p<0.05$.

and for all the KA-injected groups in comparison with salineinjected or control groups at the ipsilateral side $(p<0.01)$ (Fig. 7). No significant differences were found at the contralateral side between KA-injected, saline-injected or control groups at any area analyzed.
By day 7 pi a slight increase in neuronal numbers was observed in KA1 animals $(p<0.01)$ (Fig. 8), mainly at dorsal and ventral areas in comparison to previous days pi. KA0.75 animals also showed a slight increase in cell counting although it was not significant. This increase did not completely recover the values

Table 2

Morphometric parameters of neurons.

\begin{tabular}{|c|c|c|c|c|c|}
\hline Day pi & Control & Saline & KA075 & KA1 & KA1.25 \\
\hline & $216.39 \pm 19.48^{a}$ & - & - & - & - \\
\hline 1 & & $215.18 \pm 19.37$ & $211.63 \pm 19.06$ & $196.49 \pm 10.68$ & $193.24 \pm 14.39$ \\
\hline 2 & & $205.87 \pm 10.53$ & $199.78 \pm 9.98$ & $209.92 \pm 4.39$ & $222.97 \pm 24.07$ \\
\hline 3 & & $223.22 \pm 21.09$ & $188.28 \pm 13.95$ & $195.74 \pm 10.62$ & $205.25 \pm 18.47$ \\
\hline 7 & & $193.09 \pm 10.38$ & $227.10 \pm 21.44$ & $194.43 \pm 1.50$ & $221.05 \pm 19.89$ \\
\hline \multirow[t]{2}{*}{ Day pi } & Control & Saline & KA075 & KA1 & KA1.25 \\
\hline & $15.59 \pm 1.4^{\mathrm{d}}$ & - & - & - & - \\
\hline 1 & & $15.11 \pm 1.36$ & $15.44 \pm 4.52$ & $15.66 \pm 1.41$ & $13.56 \pm 1.22$ \\
\hline 2 & & $15.18 \pm 3.24$ & $15.04 \pm 2.34$ & $15.53 \pm 0.98$ & $14.40 \pm 1.34$ \\
\hline 3 & & $16.82 \pm 1.24$ & $14.52 \pm 1.31$ & $15.00 \pm 2.66$ & $18.45 \pm 2.98$ \\
\hline 7 & & $14.74 \pm 1.33$ & $16.47 \pm 2.67$ & $13.60 \pm 1.42$ & $15.81 \pm 3.04$ \\
\hline \multirow[t]{2}{*}{ Perimeter $(\mu \mathrm{m})$} & Control & Saline & KA075 & KA1 & KA1.25 \\
\hline & $89.67 \pm 8.07^{\mathrm{P}}$ & - & - & - & - \\
\hline 1 & & $86.95 \pm 3.54$ & $73.70 \pm 7.35$ & $70.59 \pm 6.49$ & $72.15 \pm 2.43$ \\
\hline 2 & & $81.64 \pm 7.98$ & $82.84 \pm 7.42$ & $82.31 \pm 3.11$ & $79.04 \pm 3.78$ \\
\hline 3 & & $83.26 \pm 2.71$ & $72.34 \pm 5.34$ & $78.65 \pm 8.64$ & $71.14 \pm 6.40$ \\
\hline 7 & & $63.33 \pm 2.98$ & $62.76 \pm 7.98$ & $82.72 \pm 5.34$ & $63.34 \pm 5.70$ \\
\hline \multirow[t]{2}{*}{ Roundness } & Control & Saline & KA075 & KA1 & KA1.25 \\
\hline & $2.15 \pm 0.19^{r}$ & - & - & - & - \\
\hline 1 & & $2.90 \pm 0.26$ & $2.17 \pm 0.20$ & $1.87 \pm 0.32$ & $2.27 \pm 0.76$ \\
\hline 2 & & $2.11 \pm 0.23$ & $2.05 \pm 0.23$ & $2.65 \pm 0.11$ & $1.64 \pm 0.34$ \\
\hline 3 & & $2.22 \pm 0.12$ & $2.48 \pm 0.12$ & $1.98 \pm 0.17$ & $1.77 \pm 0.21$ \\
\hline 7 & & $2.84 \pm 0.09$ & $1.47 \pm 0.45$ & $2.26 \pm 0.09$ & $2.12 \pm 0.20$ \\
\hline
\end{tabular}

a Area $\left(\mu \mathrm{m}^{2}\right)$.

d Feret diameter $(\mu \mathrm{m})$.

p Perimeter $(\mu \mathrm{m})$.

r Roundness. 


\section{Ipsilateral}
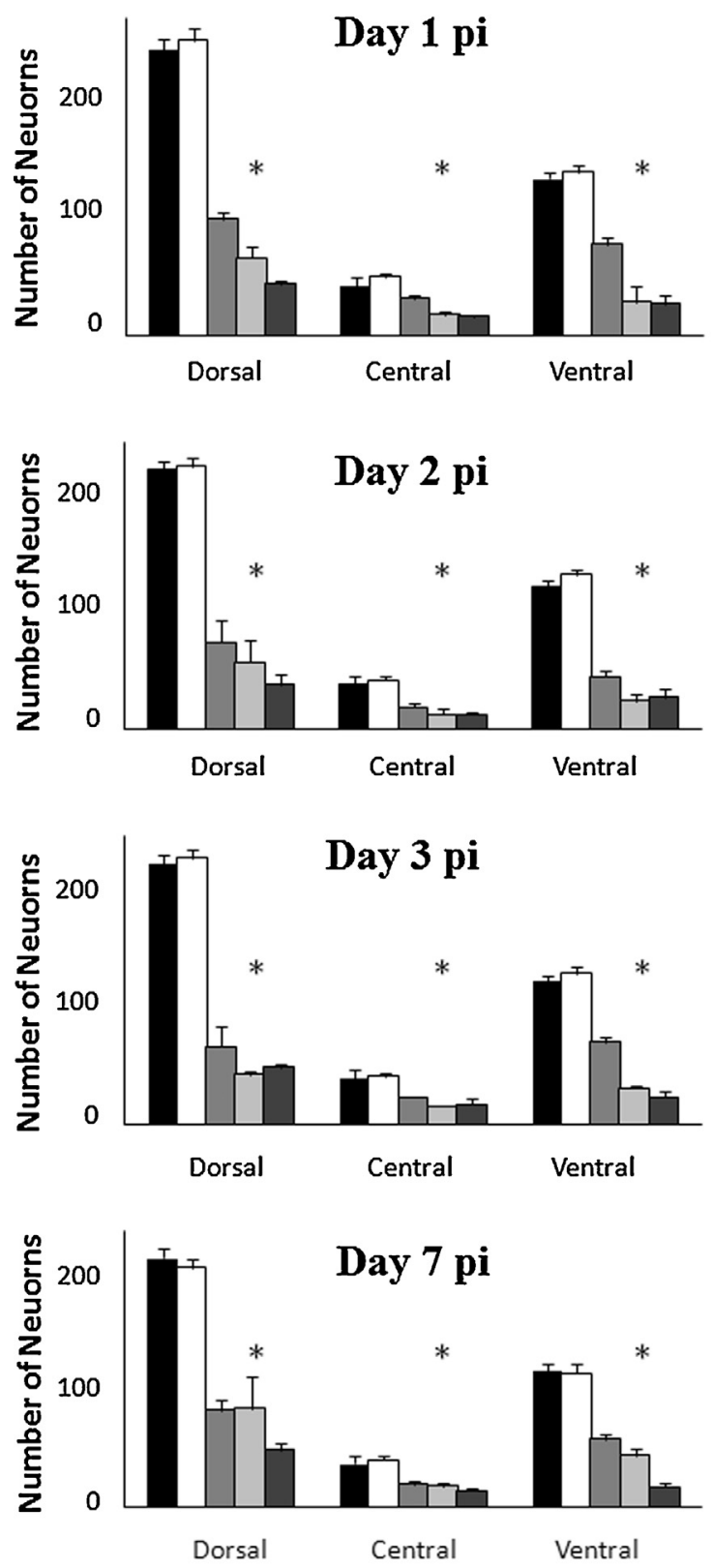

Contralateral
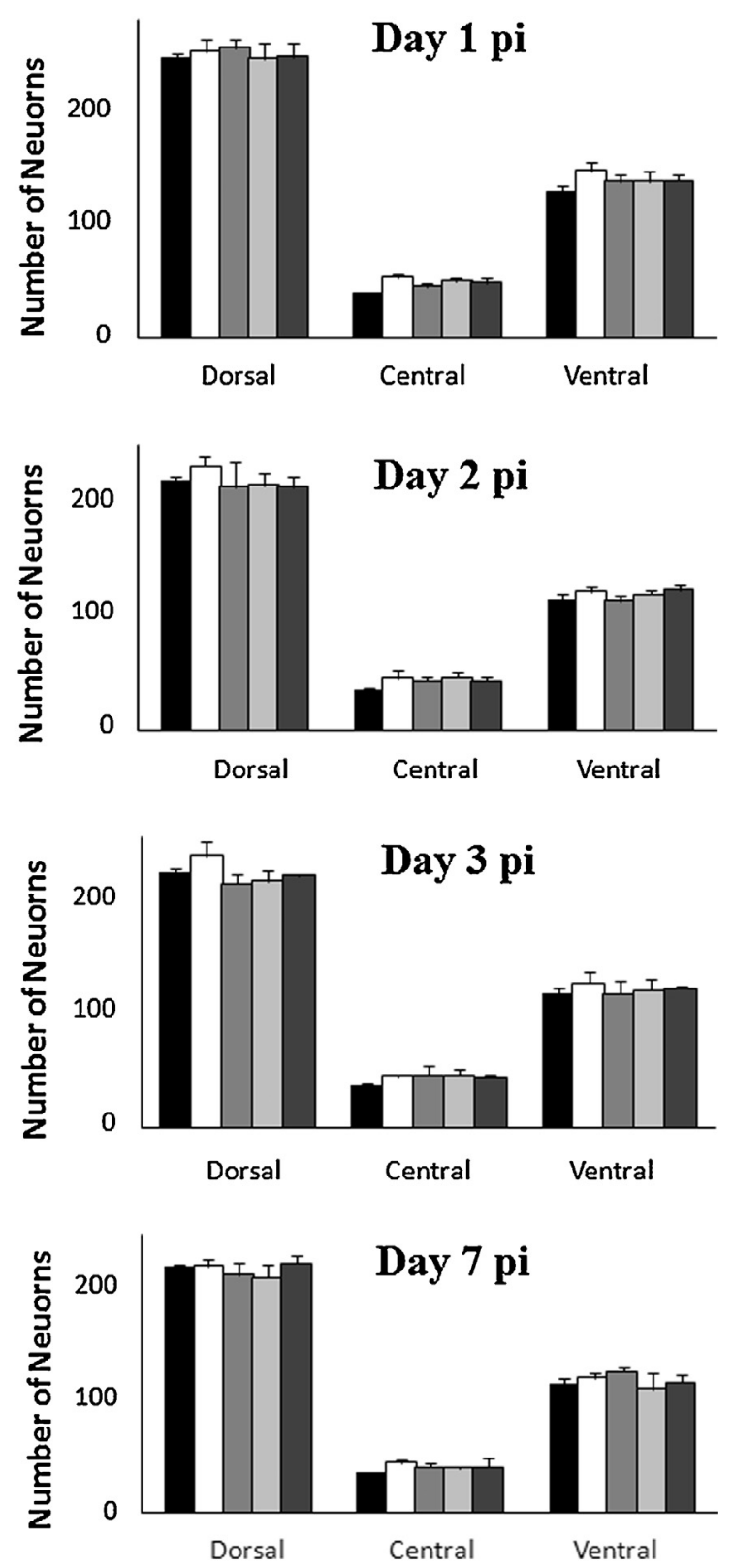

- Control $\square$ Sham $\square$ KA0.75 $\square$ KA1 $\square$ KA1.25

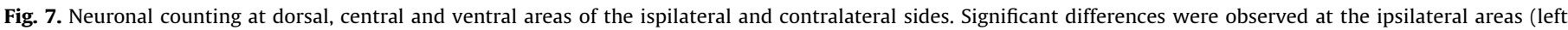

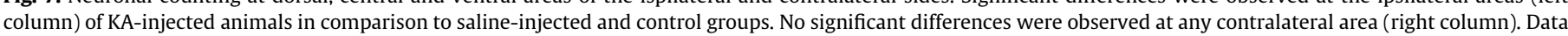
are expressed as mean \pm SEM. ${ }^{*} p<0.05$.

recorded for saline-injected or control groups. No changes were observed for the KA1.25 animal group.

Dorsal, medial and ventral areas of saline-injected and control groups showed no significant differences at any day pi neither for the ipsilateral nor for the controlateral side.

\section{Discussion}

In the present study, we showed that the intraparenchymal delivery of KA causes neuronal damage at the injection site and loss of sensory and motor functions of the ipsilateral forelimb $24 \mathrm{~h}$ after treatment in a dose-dependent manner. Although the lower doses of $\mathrm{KA}(0.75$ and $1 \mathrm{mM})$ induced a mild neuronal damage that altered the corresponding forelimb activity, rats showed a slight recovery of motor and sensory functions along the experiment. However, animals injected with the highest doses of KA (1.25 mM) showed a higher loss of neurons at the ipsilateral side of the spinal cord and no recovery at any time point.

The intrathecal injection of KA leads to neuronal death evoked by transient excitotoxicity induced by the activation of kainate and AMPA receptors (Kuzhandaivel et al., 2010; Mazzone et al., 2010; Sun et al., 2006). These receptors consist of several subunits 


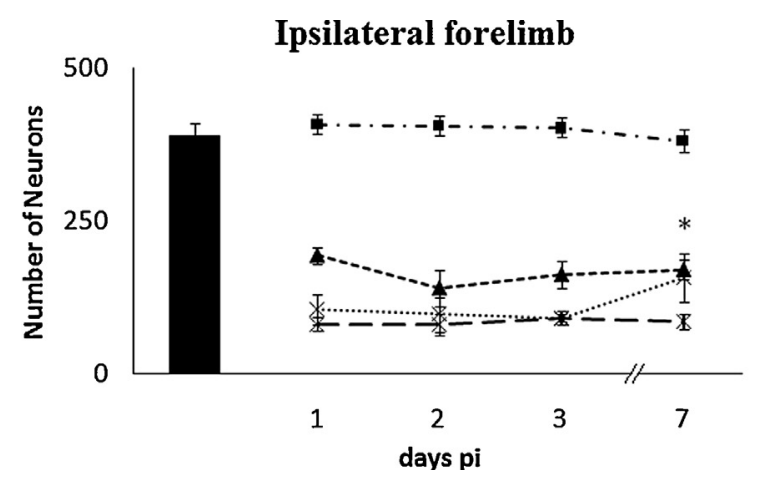

Contralateral forelimb

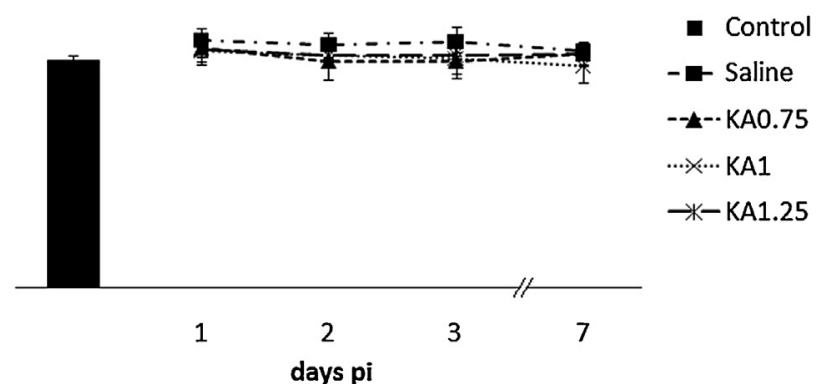

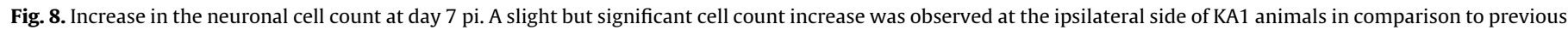
days $\left({ }^{*} p<0.05\right)$. Data are expressed as mean \pm SEM.

(GluR5, GluR6, GluR7, KA1 and KA2). The prevalence of one or another turns them more or less sensitive to KA (Lerma, 1997). KA receptors are widely distributed in the brain where the majority of the cells express the five subunits (Siegel et al., 1995). In particular, in the rat spinal cord, the kainate receptors subunits are primarily found at the most superficial laminae of the dorsal horn and ventral horn (Mazzone et al., 2010). It was suggested that the excitotoxic effect found in rats injected with kainate may be due to the presence of AMPA subunits at those zones (Tölle et al., 1993), thus contributing to the release of endogenous glutamate to act on multiple receptor subclasses (Ben Ari and Cossart, 2000).

The motor and sensory tests performed in this study also revealed a dose-related performance of the injected animals in line with the morphometric analysis of the cervical segments in which neuronal loss was higher in KA1.25 than in KA1 and KA0.75 groups. Besides, Luxol Fast Blue staining also showed large damage of the ipsilateral gray and white matter involving extensive areas of the ventral horn and the ventral and ventrolateral tracts, respectively. Based on these data, we suggest that the intraparenchymal injection of KA at C5 results in a significant functional deficit associated with ipsilateral gray and white matter damage. In spite of the tissue damage produced on the ipsilateral side, the contralateral side of the segment did not show any damage associated with the drug injection. Moreover, motor activity and sensory reflexes of the contralateral forepaw remained unaltered, thus suggesting a local effect of KA.

In the present study we have also found lesions ahead (C4) and behind (C6) the injection site (C5). We suggest that KA may have diffused to these areas through the perivascular (Virchow-Robin) space, as proposed for other organs of the CNS by Gregory et al. (1985). This diffusion may be favored by the axial arrangement of the major blood vessels present in the gray matter of the spinal cord (Scremin, 2009). As a result, the excess of fluids present in the ipsilateral side could diffuse toward the central canal using the perivascular route or the extracellular space (Nicholson, 2001), thus draining away from the region. This removal may explain the absence of lesions in the contralateral side of the spinal cord reported here. An additional interpretation may involve the presence of an anatomic and/or functional barrier that prevents the transfer of solutes between the two sides of the spinal cord, as it was observed between the third ventricle, the median eminence and the arcuate nucleus in the hypothalamus (Rodríguez et al., 2010).

According to our findings, the remnant KA that would diffuse to the central canal would have a less severe effect than that observed at the injection site since neurons in Lamina $\mathrm{X}$ were not damaged. This could be due to a delay in the arrival of the solution to the central canal caused by a slow diffusion of the liquid through the extravascular space (Nicholson, 2001). This effect could also be due to a delayed diffusion via the perivascular circulation caused by the inflammatory edema present in the area (Blaumanis et al., 1990). Finally, the absence of damage of neurons at Lamina $X$ could be due their lower sensitivity to KA than those of the dorsal and ventral Laminae, as stated by Mazzone et al. (2010).

Animals injected with the lower KA doses showed a mild improvement of their sensory and motor performance on both behavioral tests. Moreover, the histological and morphometric analysis of their segments also showed a slight increase in the number of neurons, mainly at dorsal and ventral areas of the ipsilateral side. It is known that the CNS retains certain functional plasticity to regulate and adapt the brain and spinal cord to environmental transition or injury. In this sense, uninjured neurons or axon branches can grow in denervated regions and reconstruct the neural circuits to compensate the impaired sensory and motor functions (axonal sprouting) (Chi et al., 2006; Liu et al., 2012). On the other hand, the existence of neural progenitor cells at the brain subventricular and subgranular zones is also well-known (Alvarez-Buylla and Garcia-Verdugo, 2002; Felix et al., 2012; Tong et al., 2014) and also at the subependimal zone of the spinal cord (Liu et al., 2012; Portiansky et al., 2011) that promote neurogenesis during aging (Portiansky et al., 2011), after neurodegenerative processes (Chang et al., 2008; Regensburger et al., 2014) or injury (Darian-Smith, 2009; Zhang et al., 2014). Thus, some of these processes may explain the improvement on the sensory and motor performance and the increase in the number of neurons after a week found in rats of KA0.75 and KA1 groups here reported.

Further studies are required to elucidate the mechanisms involved in the excitotoxic effect of KA. We are currently analyzing the variation on neural protein expression after the excitotoxic damage by KA.

\section{Conflict of interest}

The authors declare that there are no conflict of interests.

\section{Acknowledgements}

This work was supported by grant PICT 2012-0574 from the National Agency for Promotion of Science and Technology (ANPCyT) Argentina to ELP.

\section{Appendix A. Supplementary data}

Supplementary data associated with this article can be found, in the online version, at http://dx.doi.org/10.1016/j.neuro.2015.05.006. 


\section{References}

Alvarez-Buylla A, Garcia-Verdugo JM. Neurogenesis in adult subventricular zone. J Neurosci 2002;22:629-34.

Bayrakdar ET, Bojnik E, Armagan G, Kanit L, Benyhe S, Yalcin A. Kainic acid-induced seizure activity alters the mRNA expression and G-protein activation of the opioid/ nociceptin receptors in the rat brain cortex. Epilepsy Res 2013;105:13-9.

Ben-Ari Y, Cossart R. Kainate, a double agent that generates seizures: two decades of progress. Trends Neurosci 2000;23:580-7.

Biesiadecki BJ, Brand PH, Koch LG, Metting PJ, Britton SL. Phenotypic variation in sensorimotor performance among eleven inbred rat strains. Am J Physiol Regul Integr Comp Physiol 1999;276:1383-9.

Blaumanis OR, Rennels ML, Grady PA. Focal cerebral edema impedes convective fluid/ tracer movement through paravascular pathways in cat brain. Adv Neurol 1990;52:385-9.

Calderó J, Brunet N, Tarabal O, Piedrafita L, Hereu M, Ayala V, et al. Lithium prevents excitotoxic cell death of motoneurons in organotypic slice cultures of spinal cord. Neuroscience 2010;165:1353-69.

Chang A, Smith MC, Yin X, Fox RJ, Staugaitis SM, Trapp BD. Neurogenesis in the chronic lesions of multiple sclerosis. Brain 2008;131:2366-75.

Chi L, Ke Y, Luo C, Li B, Gozal D, Kalyanaraman B, et al. Motor neuron degeneration promotes neural progenitor cell proliferation, migration, and neurogenesis in the spinal cords of amyotrophic lateral sclerosis mice. Stem Cells 2006;24:34-43.

Chvatal SA, Kim YT, Bratt-Leal AM, Lee H, Bellamkonda RV. Spatial distribution and acute anti-inflammatory effects of methylprednisolone after sustained local delivery to the contused spinal cord. Biomaterials 2008;29:1967-75.

Corona JC, Tapia R. AMPA receptor activation, but not the accumulation of endogenous extracellular glutamate, induces paralysis and motor neuron death in rat spinal cord in vivo. J Neurochem 2004;89:988-97.

Darian-Smith C. Synaptic plasticity, neurogenesis, and functional recovery after spinal cord injury. Neuroscientist 2009;15:149-65.

Felix MS, Popa N, Djelloul M, Boucraut J, Gauthier P, Bauer S, et al. Alteration of forebrain neurogenesis after cervical spinal cord injury in the adult rat. Front Neurosci 2012;9:45. http://dx.doi.org/10.3389/fnins.2012.00045.

Gale K, Kerasidis H, Wrathall JR. Spinal cord contusion in the rat: behavioral analysis of functional neurologic impairment. Exp Neurol 1985;88:123-34.

Gregory TF, Rennels ML, Blaumanis OR, Fujimoto K. A method for microscopic studies of cerebral angioarchitecture and vascular-parenchymal relationships, based on the demonstration of 'paravascular' fluid pathways in the mammalian central nervous system. J Neurosci Methods 1985;14:5-14.

Hirata A, Nakamura R, Kwak S, Nagata N, Kamakura K. AMPA receptor-mediated slow neuronal death in the rat spinal cord induced by long-term blockade of glutamate transporters with THA. Brain Res 1997;771:37-44.

Klein A, Wessolleck J, Papazoglou A, Metz GA, Nikkhah G. Walking pattern analysis after unilateral 6-OHDA lesion and transplantation of foetal dopaminergic progenitor cells in rats. Behav Brain Res 2009;199:317-25.

Kunkel-Bagden E, Dai HN, Bregman BS. Methods to assess the development and recovery of locomotor function after spinal cord injury in rats. Exp Neurol 1993;119:153-64.

Kuzhandaivel A, Nistri A, Mladinic M. Kainate-mediated excitotoxicity induces neuronal death in the rat spinal cord in vitro via a PARP-1 dependent cell death pathway (Parthanatos). Cell Mol Neurobiol 2010;30:1001-12.

Lerma J. Kainate reveals its targets. Neuron 1997;19:1155-8.

Liu D, Xu GY, Pan E, McAdoo DJ. Neurotoxicity of glutamate at the concentration released upon spinal cord injury. Neuroscience 1999;93:1383-9.

Liu J, Yang X, Jiang L, Wang C, Yang M. Neural plasticity after spinal cord injury. Neural Plast 2012;7:386-91.

Magnuson DSK, Trinder TC, Zhang YP, Burke D, Morassutti DJ, Shields CB. Comparing deficits following excitotoxic and contusion injuries in the thoracic and lumbar spinal cord of the adult rat. Exp Neurol 1999;156:191-204.

Mazzone L, Margaryan G, Kuzhandaivel A, Nasrabady SE, Mladinic M, Nistri A. Kainateinduced delayed onset of excitotoxicity with functional loss unrelated to the extent of neuronal damage in the in vitro spinal cord. Neuroscience 2010;168:451-62.

Mazzone GL, Nistri A. Delayed neuroprotection by riloze against excitotoxic damage evoked by kainite on rat organotypic spinal cord cultures. Neuroscience 2011;190:318-27.

Matsui K, Jahr CE, Rubio ME. High-concentration rapid transients of glutamate mediate neural-glial communication via ectopic release. J Neurosci 2005;25:7538-47.
Metz GA, Whishaw IQ. Cortical and subcortical lesions impair skilled walking in the ladder rung walking test: a new task to evaluate fore- and hindlimb stepping, placing, and co-ordination. J Neurosci Methods 2002;115:169-79.

Milano J, Oliveira SM, Rossato MF, Sauzem PD, Machado P, Beck P, et al. Antinociceptive effect of novel trihalomethyl-substituted pyrazoline methyl esters in formalin and hot-plate tests in mice. Eur J Pharmacol 2008;581:86-96.

Mitra NK, Goh TE, Bala Krishnan T, Nadarajah VD, Vasavaraj AK, Soga T. Effect of intracisternal application of kainic acid on the spinal cord and locomotor activity in rats. Int J Clin Exp Pathol 2013;6:1505-15.

Nicholson C. Diffusion and related transport mechanisms in brain tissue. Rep Prog Phys 2001;64:815-84

Nishida F, Morel GR, Hereñú CB, Schwerdt JI, Goya RG, Portiansky EL. Restorative effect of intracerebroventricular insulin-like growth factor-I gene therapy on motor performance in aging rats. Neuroscience 2011;177:195-206.

Nishida F, Zanuzzi CN, Marquez M, Barbeito CG, Portiansky EL. La trepanación vertebral como un método alternativo para la inyección intraparenquimatosa de diversas suspensiones dentro de la médula espinal. Anal Vet 2014;34:11-7.

Paxinos G, Watson C. The rat brain in stereotaxic coordinates. 2nd ed. Sydney: Academic Press; 1986.

Pereno GL, Balaszczuk V, Beltramino CA. Kainic acid-induced early genes activation and neuronal death in the medial extended amygdala of rats. Exp Toxicol Pathol 2011;63:291-9.

Portiansky EL. Análisis multidimensional de imágenes digitales. La Plata, Argentina: Universidad Nacional de La Plata; 2013.

Portiansky EL, Nishida F, Barbeito CG, Gimeno EJ, Goya RG. Increased number of neurons in the cervical spinal cord of aged female rats. PLoS ONE 2011;6(2011):e22537. http://dx.doi.org/10.1371/journal.pone.0022537.

Regensburger M, Prots I, Winner B. Adult hippocampal neurogenesis in Parkinson's disease: impact on neuronal survival and plasticity. Neural Plast 2014;2014:454696.

Rodríguez EM, Blázquez JL, Guerra M. The design of barriers in the hypothalamus allows the median eminence and the arcuate nucleus to enjoy private milieus: the former opens to the portal blood and the latter to the cerebrospinal fluid. Peptides 2010:31:757-76

Sánchez HL, Silva LB, Portiansky EL, Goya RG, Zuccolilli GO. Impact of very old age on hypothalamic dopaminergic neurons in the female rat: a morphometric study. J Comp Neurol 2003;458:319-25.

Schrimsher GW, Reier PJ. Forelimb motor performance following dorsal column, dorsolateral funiculi, or ventrolateral funiculi lesions of the cervical spinal cord in the rat. Exp Neurol 1993;120:264-76.

Scremin OU. In: The Spinal Cordr., Watson C, Paxinos G, Kayalioglu G, editors. The spinal cord blood vessels. Amsterdam: Elsevier; 2009, pp. 57-63.

Sedý J, Urdzíková L, Jendelová P, Syková E. Methods for behavioral testing of spinal cord injured rats. Neurosci Biobehav Rev 2008;32:550-80.

Siegel SJ, Janssen WG, Tullai JW, Rogers SW, Moran T, Heinemann SF, et al. Distribution of the excitatory amino acid receptor subunits GluR2(4) in monkey hippocampus and colocalization with subunits GluR5-7 and NMDAR1. J Neurosci 1995:15:2707-19.

Sun H, Kawara Y, Ito K, Ichiro K, Kwak S. Slow and selective death of spinal motor neurons in vivo by intrathecal infusion of kainic acid: implications for AMPA receptor-mediated excitotoxicity in ALS. J Neurochem 2006;98:782-91.

Taccola G, Margaryan G, Mladinic M, Nistri A. Kainate and metabolic perturbation mimicking spinal injury differentially contribute to early damage of locomotor networks in the in vitro neonatal rat spinal cord. Neuroscience 2008:155:538-55.

Tölle TR, Berthele A, Zieglgansberger W, Seeburg PH, Wisden W. The differential expression of 16 NMDA and non-NMDA receptor subunits in the rat spinal cord and in periaqueductal gray. J Neurosci 1993:13:5009-28.

Tong CK, Chen J, Cebrián-Silla A, Mirzadeh Z, Obernier K, Guinto CD, et al. Axonal control of the adult neural stem cell niche. Cell Stem Cell 2014;14:500-11.

von Euler M, Akesson E, Samuelsson EB, Seiger A, Sundstrom E. Motor performance score: a new algorithm for accurate behavioral testing of spinal cord injury in rats. Exp Neurol 1996;137:242-54.

Wallace JE, Krauter EE, Campbell BA. Motor and reflexive behavior in the aging rat. J Gerontol 1980;35:364-70.

Zhang G, Vidal Pizarro I, Swain GP, Kang SH, Selzer ME. Neurogenesis in the lamprey central nervous system following spinal cord transection. J Comp Neurol $2014 ; 522: 1316-32$ 